\title{
Non-nutritive Sweeteners and Their Associations with Obesity and Type 2 Diabetes
}

\author{
Jarrett Walbolt, Yunsuk Koh* \\ Department of Health, Human Performance, and Recreation, Robbins College of Health and Human Sciences, Baylor University, Waco, TX, USA
}

Evidence linking the excessive consumption of nutritive sweeteners (NS) to adverse metabolic health outcomes has led to an increase in consumption of non-nutritive sweeteners (NNS), particularly among the obese and individuals with diabetes. NNS are characterized by having zero-to-negligible caloric load, while also having a sweet taste. They are utilized as a replacement for traditional NS to reduce energy intake and to limit carbohydrate-related negative health outcomes. However, recent studies have suggested that NNS may actually contribute to the development or worsening of metabolic diseases, including metabolic syndrome, obesity, type 2 diabetes, and cardiovascular disease. Thus, it is imperative to understand the NNS efficacy and the relationship between NNS and metabolic diseases.

Key words: Stevia, Diabetes, Aspartame, Sucralose, Glucose, Obesity

\author{
Received December 19, 2019 \\ Reviewed February 18, 2020 \\ Accepted April 9, 2020 \\ *Corresponding author \\ Yunsuk Koh \\ (iD \\ https://orcid.org/0000-0001-9280-5786 \\ Department of Health, Human \\ Performance, and Recreation, Robbins \\ College of Health and Human Sciences, \\ Baylor University, One Bear Place \\ \#97313, Waco, TX 76798, USA \\ Tel: +1-254-710-4002 \\ Fax: +1-254-710-3527 \\ E-mail:yunsuk_koh@baylor.edu
}

\section{INTRODUCTION}

Non-nutritive sweeteners (NNS) were first introduced as early as 1878 as replacements for standard table sugar. ${ }^{1} \mathrm{NNS}$ are characterized by providing few to no calories, whereas nutritive sweeteners (NS), such as standard table sugar, contain a caloric load. Both NNS and NS contribute to the flavor and texture of foods, primarily sweet taste. NNS are, however, significantly sweeter than NS, by as many thousands of times. Due to their extraordinary sweetness, much less of the substance is added to foods by consumers, thus reducing caloric intake. ${ }^{2}$ Obese and diabetic individuals use NNS to reduce caloric and carbohydrate intake for weight management, as well as for glycemic control. ${ }^{1} \mathrm{NNS}$ are derived from either chemical or natural sources. For instance, aspartame, acesulfame potassium, and sucralose are derived from chemical sources, while stevia and its extract stevioside come from natural sources.

The global market for NNS grew 5.1\% annually between 2008 and 2015. ${ }^{3}$ Consumption of NNS sweetened beverages by American adults increased from $21.1 \%$ in $2003-2004$ to $24.9 \%$ in 2009 2010. In Korea, while NNS consumption is well below acceptable daily intake levels, there is some evidence to suggest that there may be a trend towards reduced intake in recent years. ${ }^{4}$ Commercial NNS that have been approved by the United States Food and Drug Administration are listed in Table 1. During the same time span, consumption by children jumped from $7.8 \%$ to $18.9 \% .{ }^{5} \mathrm{NNS}$ consumption has become increasingly popular among women and children in particular. ${ }^{6}$ The exact reasons that NNS use has grown in these demographics is unknown, although speculations can be made. Women are more likely to attempt weight loss, ${ }^{7}$ and are therefore likely to selectively choose products labeled as "no sugar,"

Copyright (C) 2020 Korean Society for the Study of Obesity

(a) This is an Open Access article distributed under the terms of the Creative Commons Attribution Non-Commercial License (https://creativecommons.org/licenses/by-nc/4.o/) which permits unrestricted non-commercial use, distribution, and reproduction in any medium, provided the original work is properly cited. 
Table 1. Non-nutritive sweeteners approved by the United States Food and Drug Administration for use in food

\begin{tabular}{|c|c|c|c|c|}
\hline Sweetener name & ADI (mg/kg/day) & Brand name & $\begin{array}{l}\text { Times sweeter than } \\
\text { table sugar }\end{array}$ & $\begin{array}{c}\text { Number of sweetener } \\
\text { packets equivalent to ADI }\end{array}$ \\
\hline Saccharin & 15 & Sweet and Low, Sweet Twin, Sweet'N Low, and Necta Sweet & $200-700$ & 45 \\
\hline Aspartame & 50 & Nutrasweet, Equal, and Sugar Twin & 200 & 75 \\
\hline Acesulfame potassium & 15 & Sunett and Sweet One & 200 & 23 \\
\hline Sucralose & 5 & Splenda & 600 & 23 \\
\hline Neotame & 0.3 & Newtame & $7,000-13,000$ & 23 \\
\hline Advantame & 32.8 & & 20,000 & 4,920 \\
\hline Steviol glycosides & 4 & Truvia, PureVia, and Enliten & $200-400$ & 9 \\
\hline Monk fruit extract & Not specified & Nectresse, Monk Fruit in the Raw, and PureLo & $100-250$ & ADI not specified \\
\hline
\end{tabular}

$\mathrm{ADI}$, acceptable daily intake.

"diet," or "reduced sugar" that contain NNS instead of standard table sugar (sucrose). While NNS-sweetened beverage consumption has increased in adults regardless of degree of adiposity, only normal weight children showed increases. ${ }^{8}$

Obesity is linked to many adverse health outcomes, including higher risks of developing diabetes and cardiovascular disease. Obesity is no longer only a concern in Western countries, but in Asian countries as well. The Korean Society for the Study of Obesity reports a steadily increasing rate of obesity, from $29.7 \%$ in 2009 to $32.4 \%$ in $2015 .^{9}$ The associated national health care expenditure is $\$ 1.8$ billion. ${ }^{9}$ While sucrose does not directly cause diabetes, it has been linked to negative impacts on glucose tolerance in healthy individuals. ${ }^{10}$ Diets high in sucrose have also been shown to cause weight gain and obesity, which can lead to the development of diabetes. ${ }^{11}$ Large visceral fat stores cause fat cells to release proinflammatory cytokines. This puts the body into an inflammatory state, which can make insulin responsive cells insensitive to the presence of insulin. ${ }^{12}$ Compounding the insensitivity brought on by inflammation, adipose tissue may release fat molecules into the blood, which may in turn lead to additional reduced insulin sensitivity. ${ }^{13}$

Diabetes mellitus is a chronic metabolic disease that disrupts the hormonal networks responsible for stabilizing blood glucose levels through the absolute or relative hindrance of insulin secretion and/ or deficits in insulin resistance. Diabetes is a growing worldwide epidemic. In the United States alone, 30.3 million individuals, or $9.4 \%$ of the population, have diabetes. Furthermore, a staggering 84.1 million Americans have prediabetes, placing them at immediate risk of developing diabetes. ${ }^{14}$ Type 2 diabetes is characterized by a combination of $\beta$-cell dysfunction and a resistance to insulin that is released. ${ }^{15}$ Diabetes represents a significant financial burden on healthcare systems, as it accounts for more than $10 \%$ of total healthcare spending in the United States, Canada, and Europe. ${ }^{16}$ This burden is likely to increase even more in the coming years.

Research has brought the efficacy of using NNS to ameliorate or prevent metabolic diseases into scrutiny. Despite widespread usage, their supposed benefits have yet to be verified. In fact, some evidence suggests that NNS are associated with metabolic disease, particularly obesity. Since NNS have zero to very minor caloric load, they cannot contribute directly to obesity, but instead may influence metabolic processes. Research has uncovered multiple mechanisms that may play roles in how NNS could trigger metabolic disease. ${ }^{1}$

\section{ARTICLE SEARCH}

Two electronic databases (PubMed and Google Scholar) were searched for articles containing the keywords "non-nutritive sweeteners," “artificial sweeteners," "sugar substitutes," "stevia,” "aspartame," "sucralose," “acesulfame potassium," “neotame," "saccharin,” "diabetes," "metabolic disease," and "obesity." The search was limited to articles published in the English language from January 2008 to January 2019.

\section{PROSPECTIVE COHORT STUDIES OF NNS USE AND OBESITY}

As shown in Table 2, one meta-analysis examining nine prospective cohort studies reported no significant association between NNS 
Table 2. Meta-analyses of non-nutritive sweeteners

\begin{tabular}{|c|c|c|}
\hline Study & $\begin{array}{l}\text { Type (number of } \\
\text { studies included) }\end{array}$ & Variable and result \\
\hline \multirow[t]{3}{*}{ Wiebe et al. $(2011)^{25}$} & \multirow[t]{3}{*}{ RCT (53) } & Fasting blood glucose: $\leftrightarrow$ (40 studies) \\
\hline & & $\begin{array}{l}\text { Energy intake: } \downarrow \downarrow \text { ( } 2 \text { studies lasting } \\
>10 \text { weeks) }\end{array}$ \\
\hline & & Total cholesterol: $\leftrightarrow$ (7 studies) \\
\hline \multirow{4}{*}{$\begin{array}{l}\text { Onakpoya and } \\
\text { Heneghan }(2015)^{28}\end{array}$} & \multirow{4}{*}{$\begin{array}{l}\text { RCT (steviol } \\
\text { glycosides } \\
\text { only) (9) }\end{array}$} & Systolic BP: $\leftrightarrow$ (7 studies) \\
\hline & & Diastolic BP: $\downarrow \downarrow$ (11 studies) \\
\hline & & Fasting blood glucose: $\downarrow \downarrow$ (6 studies) \\
\hline & & $\begin{array}{l}\text { Total cholesterol, low-density lipoprotein, } \\
\text { high-density lipoprotein, and } \\
\text { triglycerides: } \leftrightarrow \text { (6 studies) }\end{array}$ \\
\hline \multirow[t]{4}{*}{ Toews et al. $(2019)^{19}$} & \multirow[t]{2}{*}{ RCT (21) } & BMl: $\downarrow$ (17 studies) \\
\hline & & Fasting blood glucose: $\downarrow$ (2 studies) \\
\hline & \multirow[t]{2}{*}{ Cohort (35) } & Body weight: $\uparrow \uparrow$ (4 studies) \\
\hline & & Body weight in children: $\leftrightarrow$ (1 study) \\
\hline \multirow[t]{5}{*}{ Azad et al. $(2017)^{18}$} & \multirow[t]{2}{*}{$\mathrm{RCT}(7)$} & BMl: $\leftrightarrow$ (3 studies) \\
\hline & & Body weight: $\leftrightarrow$ (5 studies) \\
\hline & \multirow[t]{3}{*}{ Cohort (30) } & BMl: $\uparrow \uparrow$ (3 studies) \\
\hline & & Body weight: $\uparrow \uparrow(2$ studies) \\
\hline & & $\begin{array}{l}\text { Metabolic syndrome and type } 2 \text { diabetes: } \\
\uparrow \uparrow \text { (13 studies) }\end{array}$ \\
\hline \multirow{7}{*}{$\begin{array}{l}\text { Miller and Perez } \\
(2014)^{17}\end{array}$} & \multirow[t]{4}{*}{ RCT (15) } & Body weight: $\downarrow \downarrow$ (15 studies) \\
\hline & & BMl: $\downarrow \downarrow$ (6 studies) \\
\hline & & Fat mass: $\downarrow \downarrow$ (6 studies) \\
\hline & & Waist circumference: $\downarrow \downarrow$ (3 studies) \\
\hline & \multirow[t]{3}{*}{ Cohort (9) } & Body weight: $\leftrightarrow$ (4 studies) \\
\hline & & Fat mass: $\leftrightarrow$ (2 studies) \\
\hline & & BMl: $\uparrow \uparrow$ (6 studies) \\
\hline
\end{tabular}

$\mathrm{RCT}$, randomized controlled trials; $\mathrm{BP}$, blood pressure; BMl, body mass index; $\leftrightarrow$, no change; $\downarrow$, small decrease; $\downarrow \downarrow$, significant decrease; $\uparrow \uparrow$, significant increase.

consumption and body weight or fat mass but did report significant links to body mass index $\left(0.03 \mathrm{~kg} / \mathrm{m}^{2} ; 95 \%\right.$ confidence interval [CI], $\left.0.01-0.06 \mathrm{~kg} / \mathrm{m}^{2}\right) .{ }^{17}$ Similar modest increases in body mass index were reported by another meta-analysis $\left(0.05 \mathrm{~kg} / \mathrm{m}^{2}\right.$; 95\% CI, $0.03-$ $0.06 \mathrm{~kg} / \mathrm{m}^{2}$ ) of 30 prospective cohort studies. ${ }^{18}$ That study reported that individuals with higher NNS consumption had increased risks for metabolic syndrome, obesity classification, cardiovascular events, and diabetes. ${ }^{18}$

A more recent meta-analysis showed similar results. ${ }^{19}$ This study obtained its data from 35 observational studies. Data from multiple studies, with a combined population of 17,934 , showed that compared to higher doses of NNS, lower doses were associated with reduced weight gain $(-0.09 \mathrm{~kg} ; 95 \% \mathrm{CI},-0.13$ to $-0.05 \mathrm{~kg})$. These results remained true in individuals who both were and were not actively trying to lose weight.
Another study utilized Framingham Heart Study data to compare regular versus diet soft drink consumption and determine risk for metabolic disease. ${ }^{20}$ The results of this analysis demonstrated that participants who consumed greater amounts of soda, whether diet or regular, had increased likelihood of showing signs of metabolic syndrome. Furthermore, NNS-sweetened diet drinks were equally associated with metabolic syndrome as regular drinks. These results were like those found in comparable studies. ${ }^{21}$ This evidence suggests that NNS use may not prevent metabolic syndrome, but rather have comparable effects to NS.

\section{RANDOMIZED, CONTROLLED TRIALS OF NNS USE AND OBESITY}

One key review of NNS effect on weight management by Rogers et al. ${ }^{22}$ utilized multiple meta-analyses of randomized, controlled trials to demonstrate potential benefits or neutral effects on obesity. Among animal studies, 62 of 90 reported decreased or equal body weight after NNS consumption. Of the 28 studies that reported weight gain, 19 used the same learning design. ${ }^{22}$ In the studies with this learning design, rats were intermittently exposed to an NNS sweetened diet, rotated with the same diet without added sweetener. $^{23-25}$ These 19 studies demonstrate concepts related to alterations in sweet taste receptors better than a link to weight gain.

To add further insights, the Rogers et al. ${ }^{22}$ study included a second meta-analysis examining short term randomized, controlled trials that compared NNS against sugar-sweetened items before an ad libitum meal. NNS were associated with reduced total energy intake ( $-94 \mathrm{kcal}$; $95 \% \mathrm{CI},-122$ to $-66 \mathrm{kcal}$ ). No difference between NNS and unsweetened waters were found ( $-2 \mathrm{kcal}$; 95\% CI, -30 to $26 \mathrm{kcal}$ ). In addition, the study included a meta-analysis of longer-term (4 weeks to 40 months) randomized controlled trials, which reported reductions of body weight with NNS interventions $(-1.35 \mathrm{~kg} ; 95 \% \mathrm{CI},-2.28$ to $-0.42 \mathrm{~kg}){ }^{22}$ A similar reduction in body weight was found when NNS interventions were compared to unsweetened water $(-1.24 \mathrm{~kg} ; 95 \% \mathrm{CI},-2.22$ to $-0.26 \mathrm{~kg})$. Other studies reported similar findings. Randomized, controlled trials of NNS show reversal or inhibition of weight gain. ${ }^{17,18}$ These data points are corroborated by a meta-analysis by Toews et al. ${ }^{19}$, which looked at two randomized, controlled trials, with a combined pop- 
ulation of 174. This showed a minor beneficial effect of NNS on body mass index $(-0.6$; $95 \% \mathrm{CI},-1.19$ to -0.01$)$. Another metaanalysis by Wiebe et al., ${ }^{25}$ looked at differences in energy intake caused by NNS use. This meta-analysis found two randomized, controlled trials that compared energy intake between a sucrose group and an NNS group. The results showed a 250-500 kcal reduction in the NNS group (95\% CI, 153-806 kcal).

\section{PROSPECTIVE COHORT STUDIES OF NNS USE AND DIABETES}

One prospective cohort study followed participants between 2000 and 2007, tracking both self-reported signs of diabetes and diet soda consumption. ${ }^{26}$ The results showed a $67 \%$ increased relative risk for type 2 diabetes in those reporting at least daily consumption of diet soda. These results were independent of baseline measures of adiposity.

A meta-analysis of prospective cohort studies evaluating NNS reported similar increased risk for diabetes among individuals who fall among the highest quartile of NNS consumption versus the lowest quartile (risk ratio [RR], 1.14; 95\% CI, 1.05-1.25). ${ }^{18}$ The relative risk was found to increase by $3 \%$ for each additional daily serving of NNS consumed (RR, 1.03; 95\% CI, 1.01-1.05). ${ }^{18}$ When compared to sugar-sweetened beverages, diet sodas have a reduced association with diabetes (population attributable fraction, $11.9 \%$; $95 \%$ CI, $7.4 \%-16.5 \%){ }^{27}$

\section{RANDOMIZED, CONTROLLED TRIALS OF NNS USE AND DIABETES}

Studies of type 2 diabetes must be long-term to measure disease development. Therefore, randomized, controlled trials tend to focus on effects of NNS on hormones associated with diabetes. The mechanisms affecting diabetes are shown in Fig. 1. The results of studies looking at NNS effect on glucose metabolism are not yet clear. Many studies are contradictory, or simply demonstrate no obvious patterns. Adiposity may be one confounding factor, but the relationship between adiposity and diabetes has not yet been fully described.

Two meta-analyses examined fasting blood glucose. Toews et al. ${ }^{19}$

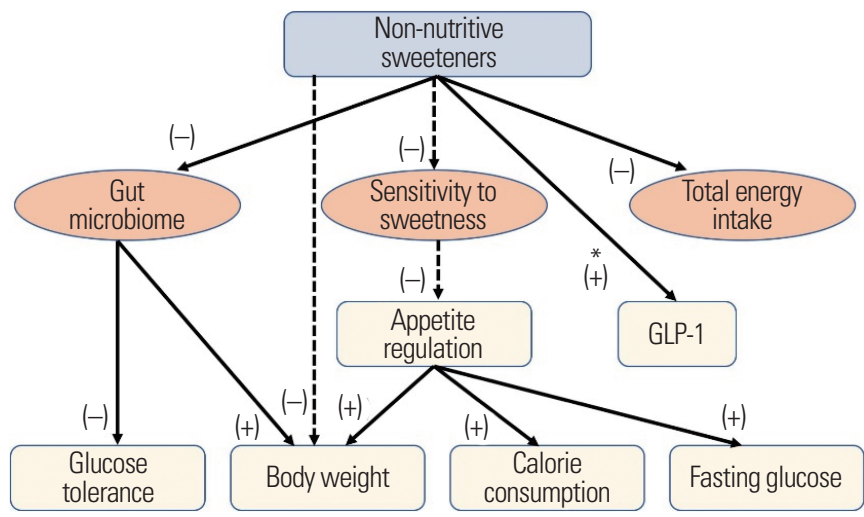

Figure 1. Non-nutritive sweeteners and mechanisms in randomized, controlled trials. *This effect is no longer seen when taste receptors are bypassed and sweeteners are delivered directly to the stomach. -, decrease; +, increase; dotted arrow, some evidence; solid arrow, strong evidence; GLP-1, glucagon-like peptide-1.

included two randomized, controlled trials with a total population of 174 and found a small reduction in glucose $(-0.16 \mathrm{mmol} / \mathrm{L} ; 95 \%$ CI, -0.26 to -0.06$)$. A meta-analysis by Onakpoya and Heneghan ${ }^{28}$ also reported similar beneficial effects on fasting blood glucose. This meta-analysis focused solely on steviol glycosides and included six studies with a total population of 521 . The results demonstrated that in randomized, controlled trials, steviol glycosides reduced fasting glucose $(-0.63 \mathrm{mmol} / \mathrm{L} ; 95 \% \mathrm{CI},-0.90$ to $-0.36 \mathrm{mmol} / \mathrm{L})$.

A minority of studies have found effects of NNS on hormonal responses. ${ }^{29,30}$ Increases in glucagon-like peptide-1 (GLP-1) have been reported in multiple studies, but this response is not observed when NNS are delivered directly to the stomach. ${ }^{31}$ This suggests that the GLP-1 response is triggered by sweet taste receptors in the mouth, rather than processes in the stomach. Generally, NNS are not thought to have significant effects on hormone responses. Many studies show no difference in response against water or similar control. ${ }^{32-34}$ Furthermore, no response is seen when NNS are used as preloads for a meal when compared to a control. ${ }^{29}$

\section{SWEET TASTE RECEPTORS}

Sweet taste begins in the oral cavity, when a sweet tastant binds to a sweet taste receptor. Sweet taste receptors are formed by Gprotein coupled receptors with two subunits (T1R2/T1R3). ${ }^{35}$ When sweet taste receptors have been triggered, neurotransmitters are released to the brain. Repeated exposure to intensely sweet tastes from natural sources results in adaptations that reduce sensi- 
tivity to sweetness. ${ }^{36}$ Reduced sensitivity to sweetness may alter the body's ability to gauge calorie intake through sweet taste by providing sweet perceptions without also providing nutrition. If this is the case, then chronic consumption of NNS would skew appetite regulation. Evidence exists to suggest that this may not be the case, as NNS have not reliably been shown to trigger such adaptations. ${ }^{37}$ The relationship between sweet taste, appetite, and caloric intake is poorly understood and lacks evidence.

Swithers et al. ${ }^{31}$ address this hypothesis through a series of experiments using similar methodologies with minor alterations made to each. All of these experiments focused on incorporating ad libitum consumption of alternating meals of plain food and either glucose or saccharin. Swithers' experiments varied in NNS delivery, duration, and diet accompanying the NNS, yet derived similar results. The findings show that rats consume more calories, gain more weight, and have higher resting glucose after intermittent saccharin consumption than intermittent glucose consumption. These findings have also been demonstrated for other NNS. ${ }^{38}$ The reason for the discrepancy between Swither's rodent studies and human studies has yet to be elucidated. Though likely multifaceted, the difference lies mostly in study design. If controlled, experimental human studies were to introduce a design focused on chronic exposure to NNS, results similar to rodent studies and prospective cohort studies may arise. Most controlled, experimental studies in humans fail to account for cumulative previous exposure or to follow NNS use long enough to see an adaptive effect from chronic use.

The aforementioned studies support the hypothesis that disturbances in the perception of caloric intake by NNS can lead to negative health outcomes. As of now, such research has not been done in humans. Unlike rats, humans are exposed to widely varying sources of food. Many sources of sweet taste and nutrition exist in the typical person's diet, thus bringing into question whether one source could cause similar shifts as those seen by Swithers et al. ${ }^{31}$ It is yet to be determined whether NNS could cause metabolic diseases such as obesity or diabetes in this way.

Recent studies observing sweetness responses to NNS brings such questions into further scrutiny. Some argue that NNS are not super-normal stimuli at all, and are thus unable to have a greater effect than sucrose. ${ }^{39}$ In other words, they are not a more intensely sweet stimulus than normal sugar. If this were the case, the basis of understanding for sweet taste receptor-based theories regarding NNS would be flawed.

Concepts about NNS and sweet taste receptor interactions are relatively new and unestablished. Further research is needed to fully understand the mechanisms underlying current observations, and to determine if sweet taste perception can affect metabolic disease risk in humans.

\section{GUT MICROBIOME}

The human gut is host to more than 100-trillion microbial cells. This complex ecosystem plays essential roles in metabolic regulation. Through symbiotic interactions with the host, the gut microbiome can alter energy metabolism. ${ }^{40}$ Although the exact mechanisms are yet unknown, the gut microbiome is believed to be associated with metabolic disease in both humans and animals. ${ }^{41,42}$ This hypothesis is supported by studies in which feces were transplanted from obese and lean mice to germ-free mice. Despite no differences in diet or caloric intake, the mice receiving transplants from obese mice gained more weight than those receiving transplants from

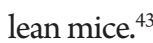

The link between the gut microbiome and NNS consumption has been noted since the early $1980 \mathrm{~s}^{44}$ At that time, saccharin exposure was shown to alter the balance between varieties of bacteria. Male rats that consumed saccharin for 10 days had a decrease of anaerobic gut bacteria and an increase in aerobic bacteria, demonstrating that specific microbiota could be targeted by dietary interventions. Furthermore, such evidence suggests that negative health effects associated with certain gut microbiota could result from NNS consumption. Animal research, particularly in livestock, has been particularly beneficial to our understanding of NNS effect on microbiota. ${ }^{45}$ NNS-sweetened livestock feed has been shown to improve feed efficiency, which is the amount of weight gained in ratio to amount of feed consumed. ${ }^{46,47}$ These studies demonstrate that NNS consumption can lead to disruptions in gut microbiota that encourage obesity and insulin resistance. While this may be ideal for producing quality livestock products, it is detrimental to the prevention of metabolic disease in humans.

Significant alterations in gut microbiome have been reported in rats that have consumed sucralose. ${ }^{48}$ Sucralose is associated with 
patterns of decreased bacterial counts and reduced bacterial diversity over time. ${ }^{49}$ Specifically, beneficial anaerobes such as bifidobacteria, lactobacilli, and Bacteroides suffered the greatest reductions, while negative enterobacteria seemed more resistant to sucralose. Negative alterations in gut microbiome species have also been shown for other sweeteners, such as aspartame..$^{50}$

A recent study by Suez et al..$^{51}$ illustrated how glucose intolerance stemming from the gut microbiota is linked to NNS consumption. In this study, saccharin, sucralose, aspartame, sucrose, and glucose were individually provided to groups of lean and obese mice. The three NNS resulted in higher markers of glucose intolerance than sucrose or glucose, with saccharin being particularly potent. The gut microbiota responded in such a way that resembled the gut environment found in individuals with type 2 diabetes. To ensure that gut microbiota were involved in glucose intolerance, researchers gave fecal transplants from saccharin-fed mice to germ free mice. The germ-free mice than began to show signs of glucose intolerance. In all mice, antibiotic treatments reversed the glucose intolerance, adding further merit to the hypothesis that the condition is associated with gut microbiota. ${ }^{51}$ These results suggest that glucose intolerance could be induced by NNS (particularly saccharin) consumption alone.

\section{A DISCREPANCY BETWEEN PROSPECTIVE COHORT AND RANDOMIZED, CONTROLLED STUDIES IN DIABETES AND OBESITY}

NNS have long been used to restrict caloric intake and prevent or reverse obesity. Studies have been divided regarding whether NNS use can be beneficial for weight management. A closer look at this divide shows that the type of study is largely indicative of whether the results will be positive, negative, or neutral. Prospective cohort studies that observe a large sample over a long period of time tend to result in negative indications regarding weight management outcomes. However, randomized, controlled studies, which have smaller samples and better controls, most often demonstrate neutral or positive benefits for NNS use.

Similar to studies of obesity, there is stark polarization between prospective cohort and randomized, controlled studies of type

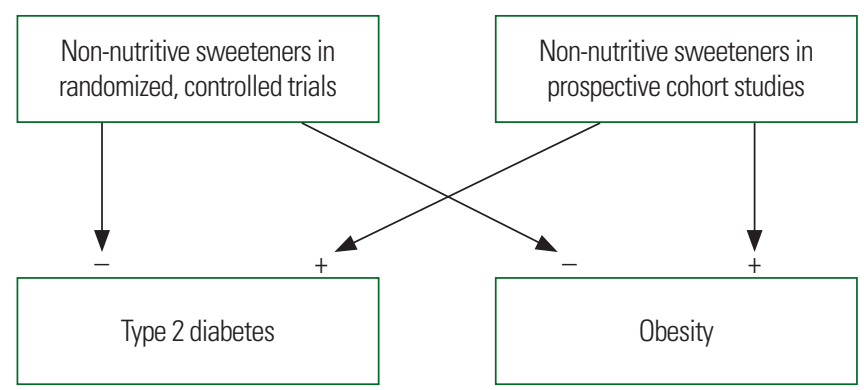

Figure 2. Associations between study type and effects on type 2 diabetes and obesity. + , increase; -, decrease.

2 diabetes. Similarly, positive outcomes are found in randomized, controlled trials, while prospective cohort studies show negative outcomes (Fig. 2). The reason for this difference between prospective cohort and randomized, controlled studies lies mostly in the controls. During prospective cohort studies, participants are free living, while additional variables are controlled in randomized, controlled trials. This results in comparisons between two very different scenarios.

Participants in prospective cohort studies are currently living without any interventions and are not part of a focused demographic. As a result, these data may be very skewed by unknown variables. For example, individuals whose consumer selections include diet beverages and other items sweetened with NNS tend to already be obese or to have diabetes. NNS are significantly more popular among obese individuals when compared to those who are normal-weight or underweight. ${ }^{6}$ Therefore, these studies are limited by reverse causality. Nevertheless, prospective cohort studies demonstrate how NNS may not actually be beneficial for improving weight management when individuals are no longer being monitored by researchers. This hypothesis is supported by rodent studies which have shown weight gain, glucose intolerance, or inflammation associated with NNS consumption. ${ }^{38,52}$ For these studies, reverse causality is not a risk, as external variables, such as consumer decisions based on body perceptions, do not exist in rodents.

Reversing this idea, the results of randomized, controlled trials demonstrate the potential benefits of a closely-monitored diet in combination with NNS consumption. These studies often include NNS in hypocaloric diets, while controlling for other variables. ${ }^{53,54}$ Their results show how NNS could be used as part of larger dietary modifications, if the individual is carefully monitoring the com- 
plete diet. Careful monitoring of the diet would also limit caloric overcompensation. This is related to the idea that an individual would believe that since they reduced their caloric intake with NNS, they can now replace those calories with other food. As a result, they perceive that what they are eating has less calories than it does. This may lead to individuals consuming more calories than they initially saved..$^{55}$

\section{FURTHER RESEARCH NEEDS}

While the topic of NNS has attracted considerable research and commanded public opinion, much about NNS has yet to be fully understood. Multiple gaps in our understanding of the links between NNS and metabolic disease remain. At this point, we are unable to determine whether NNS consumption has beneficial or negative effects on health, particularly in the context of metabolic disease. The key need is for well controlled, long-term research projects investigating NNS effects and mechanisms. While there have been many prospective cohort studies, there is a lack of studies that examine the long-term impacts of NNS in more controlled environments. Such experiments should utilize randomization to assign participants into NNS and control groups in order to eliminate the possibility of reverse causality. It would be a novel approach to design a study that is both longitudinal and well controlled. Information regarding adaptation to chronic use of NNS would therefore be gained. This knowledge would have translational importance in informing health protocols.

In addition to being inexpensive and non-invasive, diet and exercise are two of the most potent preventative methods and ways to manage, or even reverse, the onset of diabetes and obesity. ${ }^{56}$ Physical activity improves insulin response, as well as overall cardiovascular health and other physiological functions. Moderate intensity exercise is commonly suggested for individuals, with or without presence of metabolic disease. It has favorable effects on overall health, along with controlling present disease through diverse mechanisms. ${ }^{57}$

Despite the frequency with which diet and exercise in combination are prescribed, little research has been done to elucidate what, if any, effects result from the combination of NNS and exercise. A single study has examined such effects and shown that aspartame in conjunction with carbohydrates lowered insulin levels during exercise compared to carbohydrates alone. ${ }^{58}$ Further research is needed to investigate and understand the interactions between exercise and NNS.

The rising interest in child and infantile NNS consumption warrants further investigation. Babies are exposed to NNS consumed by their mother via breast milk, exposure that has been hypothesized to have potential clinical implications. ${ }^{59}$ It is unknown whether early exposure could lead to metabolic disease risks later in adulthood. Likewise, children exposed to NNS may be at increased risk for detriments to metabolic health. The current research lacks clarity on these matters ${ }^{60}$ and further research is necessary to inform recommendations for NNS use among young populations.

Certain emerging sweeteners, such as stevia, have an underwhelming presence in the literature. Currently, most studies focus on aspartame and sucralose, which are the two sweeteners that make up the majority of NNS consumption. ${ }^{3}$ Stevia represents an important research focus as it is gaining popularity the quickest. ${ }^{61}$ Additionally, as a natural low-calorie sweetener, it represents a unique target. Similarly, NNS in combination, as they are typically found in a consumer setting, are less commonly utilized. Future research should consider newer sweeteners and including NNS as they are found in the marketplace.

\section{CONCLUSION}

Researchers have yet to fully describe the long-term or acute effects of NNS consumption on metabolic diseases. Currently, the results of many studies appear contradictory, although this may be due to flaws in the two most commonly utilized study designs. Randomized, crossover designs are ideal for controlled studies, but fail to account for long term effects and human behavior in free-living scenarios. Conversely, prospective cohort studies show that NNS users are more likely to have metabolic disease but are biased, since individuals with metabolic disease are more likely to consume NNS in the first place. There is a need for research designed to combat these specific flaws.

More studies are also needed to provide insights into the mechanisms by which NNS may affect metabolic health, both positively and negatively. Research has yet to determine the effects of chronic 
NNS consumption, to see whether NNS act as a beneficial tool to combat overconsumption of carbohydrates or if NNS pose equal or greater risks as a NS.

\section{CONFLICTS OF INTEREST}

The authors declare no conflict of interest.

\section{AUTHOR CONTRIBUTIONS}

Study concept and design: all authors; drafting of the manuscript: all authors; critical revision of the manuscript: YK; and study supervision: YK.

\section{REFERENCES}

1. Shwide-Slavin C, Swift C, Ross T. Nonnutritive sweeteners: where are we today? Diabetes Spectr 2012;25:104-10.

2. Gardner C, Wylie-Rosett J, Gidding SS, Steffen LM, Johnson RK, Reader D, et al. Nonnutritive sweeteners: current use and health perspectives: a scientific statement from the American Heart Association and the American Diabetes Association. Diabetes Care 2012;35:1798-808.

3. Sylvetsky AC, Rother KI. Trends in the consumption of lowcalorie sweeteners. Physiol Behav 2016;164(Pt B):446-50.

4. Martyn D, Darch M, Roberts A, Lee HY, Yaqiong Tian T, Kaburagi N, et al. Low-/no-calorie sweeteners: a review of global intakes. Nutrients 2018;10:357.

5. Piernas C, Ng SW, Popkin B. Trends in purchases and intake of foods and beverages containing caloric and low-calorie sweeteners over the last decade in the United States. Pediatr Obes 2013;8:294-306.

6. Sylvetsky AC, Welsh JA, Brown RJ, Vos MB. Low-calorie sweetener consumption is increasing in the United States. Am J Clin Nutr 2012;96:640-6.

7. Piernas C, Aveyard P, Jebb SA. Recent trends in weight loss attempts: repeated cross-sectional analyses from the health survey for England. Int J Obes (Lond) 2016;40:1754-9.

8. Miller G, Merlo C, Demissie Z, Sliwa S, Park S. Trends in beverage consumption among high school students: United States,
2007-2015. MMWR Morb Mortal Wkly Rep 2017;66:112-6.

9. Seo MH, Lee WY, Kim SS, Kang JH, Kang JH, Kim KK, et al. 2018 Korean Society for the Study of Obesity Guideline for the Management of Obesity in Korea. J Obes Metab Syndr 2019;28:40-5.

10. Cohen AM, Teitelbaum A, Balogh M, Groen JJ. Effect of interchanging bread and sucrose as main source of carbohydrate in a low fat diet on the glucose tolerance curve of healthy volunteer subjects. Am J Clin Nutr 1966;19:59-62.

11. Malik VS, Schulze MB, Hu FB. Intake of sugar-sweetened beverages and weight gain: a systematic review. Am J Clin Nutr 2006;84:274-88.

12. Dandona P, Aljada A, Bandyopadhyay A. Inflammation: the link between insulin resistance, obesity and diabetes. Trends Immunol 2004;25:4-7.

13. Kahn BB, Flier JS. Obesity and insulin resistance. J Clin Invest 2000;106:473-81.

14. Centers for Disease Control and Prevention. National diabetes statistics report: estimates of diabetes and its burden in the United States. Atlanta (GA): Centers for Disease Control and Prevention; 2014.

15. American Diabetes Association. Diagnosis and classification of diabetes mellitus. Diabetes Care 2014;37(Suppl 1):S81-90.

16.Zhang P, Zhang X, Brown J, Vistisen D, Sicree R, Shaw J, et al. Global healthcare expenditure on diabetes for 2010 and 2030. Diabetes Res Clin Pract 2010;87:293-301.

17. Miller PE, Perez V. Low-calorie sweeteners and body weight and composition: a meta-analysis of randomized controlled trials and prospective cohort studies. Am J Clin Nutr 2014; 100:765-77.

18. Azad MB, Abou-Setta AM, Chauhan BF, Rabbani R, Lys J, Copstein L, et al. Nonnutritive sweeteners and cardiometabolic health: a systematic review and meta-analysis of randomized controlled trials and prospective cohort studies. CMAJ 2017; 189:E929-39.

19. Toews I, Lohner S, Küllenberg de Gaudry D, Sommer H, Meerpohl JJ. Association between intake of non-sugar sweeteners and health outcomes: systematic review and meta-analyses of randomised and non-randomised controlled trials and observational studies. BMJ 2019;364:k4718. 
20. Dhingra R, Sullivan L, Jacques PF, Wang TJ, Fox CS, Meigs $\mathrm{JB}$, et al. Soft drink consumption and risk of developing cardiometabolic risk factors and the metabolic syndrome in middleaged adults in the community. Circulation 2007;116:480-8.

21. Lutsey PL, Steffen LM, Stevens J. Dietary intake and the development of the metabolic syndrome: the atherosclerosis risk in communities study. Circulation 2008;117:754-61.

22. Rogers PJ, Hogenkamp PS, de Graaf C, Higgs S, Lluch A, Ness AR, et al. Does low-energy sweetener consumption affect energy intake and body weight? A systematic review, including meta-analyses, of the evidence from human and animal studies. Int J Obes (Lond) 2016;40:381-94.

23. Swithers SE, Sample CH, Davidson TL. Adverse effects of high-intensity sweeteners on energy intake and weight control in male and obesity-prone female rats. Behav Neurosci 2013; 127:262-74

24. Swithers SE, Davidson TL. A role for sweet taste: calorie predictive relations in energy regulation by rats. Behav Neurosci 2008;122:161-73.

25. Wiebe N, Padwal R, Field C, Marks S, Jacobs R, Tonelli M. A systematic review on the effect of sweeteners on glycemic response and clinically relevant outcomes. BMC Med 2011;9: 123.

26. Nettleton JA, Lutsey PL, Wang Y, Lima JA, Michos ED, Jacobs DR Jr. Diet soda intake and risk of incident metabolic syndrome and type 2 diabetes in the Multi-Ethnic Study of Atherosclerosis (MESA). Diabetes Care 2009;32:688-94.

27. Imamura F, O’Connor L, Ye Z, Mursu J, Hayashino Y, Bhupathiraju SN, et al. Consumption of sugar sweetened beverages, artificially sweetened beverages, and fruit juice and incidence of type 2 diabetes: systematic review, meta-analysis, and estimation of population attributable fraction. Br J Sports Med 2016; 50:496-504

28. Onakpoya IJ, Heneghan CJ. Effect of the natural sweetener, steviol glycoside, on cardiovascular risk factors: a systematic review and meta-analysis of randomised clinical trials. Eur J Prev Cardiol 2015;22:1575-87.

29. Anton SD, Martin CK, Han H, Coulon S, Cefalu WT, Geiselman P, et al. Effects of stevia, aspartame, and sucrose on food intake, satiety, and postprandial glucose and insulin levels. Ap- petite 2010;55:37-43.

30. Pepino MY, Tiemann CD, Patterson BW, Wice BM, Klein S. Sucralose affects glycemic and hormonal responses to an oral glucose load. Diabetes Care 2013;36:2530-5.

31. Swithers SE, Laboy AF, Clark K, Cooper S, Davidson TL. Experience with the high-intensity sweetener saccharin impairs glucose homeostasis and GLP-1 release in rats. Behav Brain Res 2012;233:1-14.

32. Brown AW, Bohan Brown MM, Onken KL, Beitz DC. Shortterm consumption of sucralose, a nonnutritive sweetener, is similar to water with regard to select markers of hunger signaling and short-term glucose homeostasis in women. Nutr Res 2011;31:882-8.

33. Okuno G, Kawakami F, Tako H, Kashihara T, Shibamoto S, Yamazaki T, et al. Glucose tolerance, blood lipid, insulin and glucagon concentration after single or continuous administration of aspartame in diabetics. Diabetes Res Clin Pract 1986; 2:23-7.

34. Ma J, Bellon M, Wishart JM, Young R, Blackshaw LA, Jones $\mathrm{KL}$, et al. Effect of the artificial sweetener, sucralose, on gastric emptying and incretin hormone release in healthy subjects. Am J Physiol Gastrointest Liver Physiol 2009;296:G735-9.

35. Bachmanov AA, Bosak NP, Lin C, Matsumoto I, Ohmoto M, Reed DR, et al. Genetics of taste receptors. Curr Pharm Des 2014;20:2669-83.

36. Tonosaki K, Funakoshi M. Cross-adapted sugar responses in the mouse taste cell. Comp Biochem Physiol A Comp Physiol 1989;92:181-3.

37.Johnson RJ, Sánchez-Lozada LG, Andrews P, Lanaspa MA. Perspective: a historical and scientific perspective of sugar and its relation with obesity and diabetes. Adv Nutr 2017;8:412-22.

38. Feijó FM, Ballard CR, Foletto KC, Batista BA, Neves AM, Ribeiro MF, et al. Saccharin and aspartame, compared with sucrose, induce greater weight gain in adult Wistar rats, at similar total caloric intake levels. Appetite 2013;60:203-7.

39. Antenucci RG, Hayes JE. Nonnutritive sweeteners are not supernormal stimuli. Int J Obes (Lond) 2015;39:254-9.

40. Bäckhed F, Ding H, Wang T, Hooper LV, Koh GY, Nagy A, et al. The gut microbiota as an environmental factor that regulates fat storage. Proc Natl Acad Sci U S A 2004;101:15718-23. 
41.Ley RE, Bäckhed F, Turnbaugh P, Lozupone CA, Knight RD, Gordon JI. Obesity alters gut microbial ecology. Proc Natl Acad Sci U S A 2005;102:11070-5.

42. Turnbaugh PJ, Ley RE, Mahowald MA, Magrini V, Mardis ER, Gordon JI. An obesity-associated gut microbiome with increased capacity for energy harvest. Nature 2006;444:1027-31.

43. Kulecka M, Paziewska A, Zeber-Lubecka N, Ambrozkiewicz F, Kopczynski M, Kuklinska U, et al. Prolonged transfer of feces from the lean mice modulates gut microbiota in obese mice. Nutr Metab (Lond) 2016;13:57.

44. Anderson RL, Kirkland JJ. The effect of sodium saccharin in the diet on caecal microflora. Food Cosmet Toxicol 1980;18: 353-5.

45. Daly K, Darby AC, Hall N, Nau A, Bravo D, Shirazi-Beechey SP. Dietary supplementation with lactose or artificial sweetener enhances swine gut Lactobacillus population abundance. $\mathrm{Br} \mathrm{J}$ Nutr 2014;111 Suppl 1:S30-5.

46. Sterk A, Schlegel P, Mul AJ, Ubbink-Blanksma M, Bruininx EM. Effects of sweeteners on individual feed intake characteristics and performance in group-housed weanling pigs. J Anim Sci 2008;86:2990-7.

47. Siurana A, Wall EH, Rodrguez M, Castillejos L, Ferret A, Calsamiglia $\mathrm{S}$. The effect of dietary supplementation of artificial sweetener on performance of milk-fed calves. Proceedings of 2014 ADSA-ASAS-CSAS Joint Annual Meeting; 2014 Jul 22; Kansas City, MI, USA.

48. Abou-Donia MB, El-Masry EM, Abdel-Rahman AA, McLendon RE, Schiffman SS. Splenda alters gut microflora and increases intestinal p-glycoprotein and cytochrome p-450 in male rats. J Toxicol Environ Health A 2008;71:1415-29.

49. Scher JU, Ubeda C, Artacho A, Attur M, Isaac S, Reddy SM, et al. Decreased bacterial diversity characterizes the altered gut microbiota in patients with psoriatic arthritis, resembling dysbiosis in inflammatory bowel disease. Arthritis Rheumatol 2015;67:128-39.

50. Palmnäs MS, Cowan TE, Bomhof MR, Su J, Reimer RA, Vogel HJ, et al. Low-dose aspartame consumption differentially affects gut microbiota-host metabolic interactions in the diet- induced obese rat. PLoS One 2014;9:e109841.

51. Suez J, Korem T, Zeevi D, Zilberman-Schapira G, Thaiss CA, Maza O, et al. Artificial sweeteners induce glucose intolerance by altering the gut microbiota. Nature 2014;514:181-6.

52. Choudhary AK, Pretorius E. Revisiting the safety of aspartame. Nutr Rev 2017;75:718-30.

53. Peters JC, Beck J, Cardel M, Wyatt HR, Foster GD, Pan Z, et al. The effects of water and non-nutritive sweetened beverages on weight loss and weight maintenance: a randomized clinical trial. Obesity (Silver Spring) 2016;24:297-304.

54. Blackburn GL, Kanders BS, Lavin PT, Keller SD, Whatley J. The effect of aspartame as part of a multidisciplinary weightcontrol program on short- and long-term control of body weight. Am J Clin Nutr 1997;65:409-18.

55. Beauchamp GK. Why do we like sweet taste: a bitter tale? Physiol Behav 2016;164(Pt B):432-7.

56. Appuhamy JA, Kebreab E, Simon M, Yada R, Milligan LP, France J. Effects of diet and exercise interventions on diabetes risk factors in adults without diabetes: meta-analyses of controlled trials. Diabetol Metab Syndr 2014;6:127.

57. You T, Arsenis NC, Disanzo BL, Lamonte MJ. Effects of exercise training on chronic inflammation in obesity: current evidence and potential mechanisms. Sports Med 2013;43:243-56.

58. Siegler J, Howell K, Vince R, Bray J, Towlson C, Peart D, et al. Aspartame in conjunction with carbohydrate reduces insulin levels during endurance exercise. J Int Soc Sports Nutr 2012; 9:36.

59. Sylvetsky AC, Gardner AL, Bauman V, Blau JE, Garraffo HM, Walter PJ, et al. Nonnutritive sweeteners in breast milk. J Toxicol Environ Health A 2015;78:1029-32.

60. Reid AE, Chauhan BF, Rabbani R, Lys J, Copstein L, Mann A, et al. Early exposure to nonnutritive sweeteners and long-term metabolic health: a systematic review. Pediatrics 2016;137: e20153603.

61. Hackett M, Bland A, Ma X, Yokose K. Chemical economics handbook report: high intensity sweeteners. Menlo Park (CA): SRI International; 2014. 